\title{
La cartografía de los temores: las web del delito en Iberoamérica ${ }^{1}$
}

\author{
Pedro Fraile ${ }^{2}$ y Quim Bonastra ${ }^{3}$
}

\begin{abstract}
RESUMEN
Desde finales del pasado siglo ha habido un incremento importante de la web 2.0 que permite al usuario introducir información, contribuyendo así a configurarla. En este ambiente, ha proliferado en todo el mundo, aunque con diferencias regionales importantes, una cartografía de delitos y conflictos fundamentalmente urbanos, para la que a menudo se pide la colaboración de las personas, que se ha denominado web del delito. En este artículo se estudiará este fenómeno en América Latina a finales de 2010, donde encontramos dieciocho de estos lugares en internet. Se investigará su titularidad y su contenido, así como el formato que adoptan. Se contextualizarán en su ámbito territorial con la intención de establecer diferentes categorías y encontrar regularidades que permitan explicar su funcionamiento y su influencia espacial.
\end{abstract}

Palabras clave: Delincuencia urbana, TIC, Delincuencia en Iberoamérica, web del delito.

\begin{abstract}
Since the end of the last century, there has been significant growth in the use of Web 2.0, which allows the user to enter information and thus make a contribution to its configuration. In this context throughout the world, though with marked regional differences, a mapping of predominantly urban crimes and conflicts has developed, for which individual and group collaborations are often requested. This article will analyze the eighteen webs of crime existing in Latin America during the year 2010. We will conduct research on their leadership, their membership and their format. We will put them on the context of the territory they are related to. The intention is to establish different categories and find the regularities that explain how these webs operate and their spatial influence.
\end{abstract}

Key Words: Urban Crime, Information and Communication Technologies, Crime in Latin America, Online Crime Mapping.

1 El presente artículo es parte de una investigación más amplia financiada por el Ministerio de Ciencia e Innovación de España que lleva por título Delito, conflicto, seguridad y paisaje urbano en ciudades intermedias de Cataluña: los casos de Gerona, Tarragona y Lleida (CSO2008-02746GEOG). Artículo recibido el 14 de febrero de 2012, aceptado el 19 de agosto de 2012 y corregido el 14 de septiembre de 2012.

2 Departamento de Geografía y Sociología, Universidad de Lleida (España).

E-mail: pedrofrl@telefonica.net

3 Departamento de Geografía y Sociología, Universidad de Lleida (España).

E-mail: quim.bonastra@geosoc.udl.cat 
Este trabajo se entronca en una investigación más amplia, que tiene por objetivo estudiar la relación existente entre la percepción de seguridad y ciertos factores territoriales. En tal reflexión partimos de la idea de que existe un flujo en ambas direcciones, es decir, determinadas configuraciones espaciales influyen en la sensación de seguridad de sus usuarios $y$, a su vez, la vivencia que ellos tienen de un entorno concreto condiciona el uso que hacen de él, así como las estrategias que ponen en marcha para modificarlo o, quizás, esquivarlo.

Aunque este debate sería largo, algunos autores ya han señalado que la sensación de seguridad no es algo objetivo, ni mucho menos mensurable con precisión, por su alta carga de subjetividad (Fraile et al., 2006; Fraile et al., 2010). Como tal fenómeno complejo no obedece a una única causa, ni siquiera a una clara nebulosa causal que pudiese explicarlo, son muchos, por tanto, los elementos que intervienen en la formación de tal percepción, a menudo con una jerarquía cambiante. Con frecuencia, algunos conflictos, discrepancias en el uso del espacio público o la divulgación de algunas noticias o rumores pueden incidir de manera determinante en la vivencia de los lugares ${ }^{4}$ y en la configuración de la sensación de seguridad que se vincula a ellos. Desde ese punto de vista, los sitios web en los que se cartografían delitos, pueden tener una influencia notable en tal sentido y su difusión puede orientar la percepción de una parte importante de la población, de ahí el interés de su estudio.

Puesto que internet y la web son elementos harto conocidos, no entraremos en detalles, pero sí haremos un esbozo que ayude a enmarcar nuestro trabajo. Desde finales del siglo pasado, con la expansión de la Web 2.0 y el desarrollo de los mashup ${ }^{5}$, han proliferado páginas, la mayoría sobre el soporte de Google Maps, donde se sitúan diferentes hechos que, en un principio, deberían ser delictivos, condicionando así la imagen de

\footnotetext{
4 En relación con la percepción es interesante Lindón et al., 2006. También Lindón, 2007. Sobre los mapas mentales Castro, 1997 y Castro, 2004.

5 Este término hace referencia a la mezcla de diferentes aplicaciones, como se explicará más adelante.
}

ciertas áreas. De modo que si una zona, en el mapa de una ciudad cualquiera, parece concentrar, por ejemplo, los robos con violencia, probablemente será percibida como peligrosa por quienes consultan tal cartografía y lógicamente ello repercutirá en su comportamiento espacial, lo que, según el grado de difusión, puede alterar la vivencia social de ese lugar. Por eso parece imprescindible abordar su análisis desde una perspectiva geográfica.

Fraile y Bonastra (2010) han planteado una primera aproximación al panorama general de estas páginas, a partir del estudio de ciento cincuenta de ellas de todo el mundo -lo que, aunque no sea una muestra con rigor estadístico, sí es suficientemente representativa y útil para obtener una idea amplia de lo que está sucediendo-. Los factores que abonaron el terreno para el despliegue de estos sitios web fueron, según los autores, básicamente de tres tipos. Por un lado la consolidación, en la reflexión penológica, de una línea de pensamiento denominada lógica actuarial $^{6}$, por otro, la existencia de una reflexión geográfica sobre conflictos y delitos $y$, finalmente, la generalización de un discurso sobre la participación ciudadana y su utilidad para legitimar los más diversos procesos de intervención social y territorial, participación a la que, a menudo, se le exigían pocos requisitos ${ }^{7}$.

El estudio anteriormente mencionado (Fraile y Bonastra, 2010) muestra que, en este contexto, su proliferación se dio, básicamente, en el mundo anglosajón, ya que aproximadamente dos tercios del total eran estadounidenses, seguidas a distancia por Gran

\footnotetext{
6 Por lógica actuarial se entiende aquella que defiende como línea estratégica de intervención la que se limita a la gestión de los riesgos, soslayando la actuación sobre sus causas. Se puede encontrar una reflexión crítica en Hebberecht, 2003. También en Domínguez y Rodríguez, 2003. Sobre la idea de sociedad del riesgo es inexcusable Beck, 2002.

7 Es fundamental, para un análisis crítico de la literatura sobre la participación ciudadana en la intervención territorial Fracasso, 2000. Sobre lo acaecido, a finales del siglo XX, en la planificación urbana Campos, 1990. Hay una crítica a tales procedimientos participativos en Healey, 1997.
} 
Bretaña, Australia y el Canadá anglófono. Es significativa su debilidad en Europa.

Otro aspecto de la mayor relevancia es su titularidad. En general, en el mencionado ámbito anglosajón, la mayoría depende de departamentos de policía o de otras agencias gubernamentales relacionadas con el control del delito. El segundo responsable en importancia es la prensa, seguida por lo que podríamos denominar empresas de tecnología que, por lo general, aunque ofrecen alguna información al público, se dedican a vender sus servicios cartográficos y de análisis a entidades diversas, sean ayuntamientos o departamentos policiales. Existen también algunas que combinan diferentes titularidades. Finalmente, es preciso hacer hincapié en aquellas que dependen de particulares o de ONG que, aunque poco significativas en el conjunto, tienen una importancia considerable en ámbitos como América Latina, como podremos comprobar.

Un factor decisivo para comprender, tanto el impacto territorial como el uso político que se puede hacer de tales páginas, es saber de dónde proviene la información. Las tres cuartas partes, de las 150 analizadas en el estudio, tienen su origen en registros policiales, como era presumible, y alrededor de un $10 \%$ se basan en los datos proporcionados por los particulares, lo que es digno de ser señalado porque tendrá una cierta importancia en el caso iberoamericano. El resto suele utilizar una mezcla de estas fuentes, a menudo en porcentajes variables según la información disponible en cada lugar, un buen ejemplo de lo cual puede ser la web de Estados Unidos SpotCrime.

Finalmente, queda otra pregunta relevante: ¿qué y cómo se cartografía? Por lo general, en estos sitios web, se representan aquellos delitos que producen mayor alarma social, como asesinatos, atracos, hurtos, robos en domicilios, incendios provocados, tráfico de drogas etc. A menudo adolecen de una definición precisa de lo que hay tras cada concepto, lo que contribuye a generar una cierta confusión y una escora hacia el alarmismo. Respecto a la estética, es preciso reconocer que, habitualmente, es bastante neutra, aproximándose a lo que sería un "mapa de chinchetas", aunque, en ocasiones, se tiende al icono tremendista, como por ejemplo una pistola cuando se trata de robos, sin especificar si ha habido violencia o no y que, a menudo, están mezclados con los hurtos. Tal tipo de representación contribuye a crear ese clima de inseguridad y prevención bastante relacionado con la web del delito.

En resumen, estamos frente a una herramienta muy potente que, a su vez, encierra algunos peligros dignos de consideración. Por un lado porque tiende a confundir la cartografía con la realidad, lo que tiene una influencia notable sobre la vida cotidiana de los individuos, sobre el uso que se hace del espacio público y, lógicamente, ambas cosas repercuten sobre los vínculos que se establecen entre las personas, sobre la valoración o estigmatización de grupos y colectivos o sobre las formas o las posibilidades de reforzar la cohesión social. Por otro, por el sesgo y el escaso rigor de la información introducida, lo que puede crear confusión y propiciar su utilización tendenciosa o partidista.

A la luz de este panorama general, en este artículo nos centraremos en el caso de América Latina, para lo cual estudiaremos todas las páginas, dieciocho en total, que estaban en funcionamiento en ese ámbito territorial a final de 2010 y seleccionaremos los siete países (Argentina, Brasil, Chile, Colombia, Ecuador, México y Venezuela) que contaban con ellas.

El objetivo que perseguimos es analizar estas web, lo que nos llevará a indagar sobre su titularidad, sobre su contenido y la forma en que este se muestra, así como sobre el contexto económico, político y social en que esto sucede. En definitiva, nos interesa saber qué y cómo se cartografía para intentar relacionarlo con aquellas personas o entidades que promueven tales iniciativas. Superaremos la mera descripción del fenómeno en busca de regularidades que sean significativas. En consecuencia, no estudiaremos aquí las repercusiones inmediatas en su entorno social, pues desbordaría los límites de estas páginas, por lo que habrá que acometerlas en otra publicación.

En lo sustancial, la aparición y proliferación de estas web obedece a las condiciones generales que han propiciado la implanta- 
ción y expansión de las Tecnologías de la Información y la Comunicación (TIC) en todo el mundo, así como al éxito que están teniendo en el ámbito anglosajón. Por ello analizaremos, en la primera parte, aquellas transformaciones en internet y en la web que han abonado el terreno para su expansión. En la segunda nos adentraremos en el caso concreto de América Latina y contextualizaremos mediante diferentes variables lo que está sucediendo en los distintos países.

Finalmente, conviene señalar que, en el momento de la aparición de este artículo, es posible que algunas de las web referidas hayan desaparecido o aparecido otras nuevas, como consecuencia de los vertiginosos cambios de los contenidos en internet. Las cribas exigidas por las revistas científicas, para asegurar la calidad de los manuscritos recibidos, hacen que estos se publiquen tiempo después de su presentación.

\section{Cómo internet contribuye a modelar el espacio}

Castells ya explicó hace tiempo que en los momentos de profundos cambios económicos y sociales las transformaciones relevantes, aunque relacionadas con los productos, recaen fundamentalmente en los procesos que estos generan (Castells, 1995: 39) y recurre al ejemplo del ferrocarril en la segunda mitad del ochocientos para corroborar tal aseveración.

Lo mismo está ocurriendo en lo que este autor denomina la era informacional. El ordenador, las herramientas relacionadas con las TIC, así como la transmisión de datos en tiempo real que posibilita internet, están alterando el mundo en muchos aspectos ${ }^{8}$, modificando la relación capital/trabajo, marcando nuevas pautas para la localización industrial y así un largo etcétera de cambios que están configurando la economía y la sociedad de comienzos del siglo XXI. Pero, a su vez, está menos analizado cómo todas estas transfor-

\footnotetext{
8 La educación es uno de esos aspectos que están cambiando profundamente. Aunque no nos ocuparemos de ello en esta páginas, vale la pena señalar el siguiente trabajo: Capel, 2009.
}

maciones influyen en la vida cotidiana de las personas, así como en su uso del espacio en el quehacer diario. Todavía son escasos los estudios sobre cómo este nuevo panorama informacional condiciona la vivencia del entorno o cómo modifica la relación entre las personas, los lugares que les son próximos o la ciudad en su conjunto.

Desde nuestro punto de vista, uno de los elementos emergentes, en este nuevo modo de desarrollo, que está produciendo efectos en este sentido, es la web del delito que, tal como hemos dicho, modula percepciones y condiciona relaciones espaciales, aspectos ambos determinantes de la vida cotidiana de los individuos. Por tanto, su estudio es una contribución para diseñar un modelo explicativo de las repercusiones que las nuevas dinámicas socioeconómicas tienen en la escala urbana. Ahora bien, el primer paso para avanzar en tal dirección es el análisis del fenómeno de la web en sí mismo, condición indispensable para, con posterioridad y en otra publicación, adentrarse en sus repercusiones sobre la percepción y el uso del espacio público.

La expansión de la web del delito, en aquellos países de América Latina que disponen de ellas, obedece a dinámicas de carácter global, que propician que las TIC tengan una importancia creciente en las relaciones económicas y sociales, por lo que nos detendremos en ellas para diseñar un marco general en el que situar nuestro objeto de estudio.

\section{Pasado y presente de la web}

La versión inicial de la web, que conocimos como un depósito de información en la red, sin duda, resultó muy útil en su momento, aunque no fuese más que por su capacidad de almacenamiento. Pero las cosas cambiaron sustancialmente a principios de este siglo, cuando se produjo el salto hacia lo que dio en llamarse la web 2.0, expresión acuñada en $2004^{9}$ que pretendía incidir en la idea de que estábamos frente a una nueva versión con mayores potencialidades: básicamente

\footnotetext{
9 Sobre los cambios y la potencialidad de la web 2.0 es interesante Pisani y Piotet, 2009.
} 
por la posibilidad de que el usuario colocase, a su vez, información, generando así una espiral de configuración y crecimiento.

En términos de Pisani y Piotet (2009) se estaba pasando del internauta, que se movía por la red en busca de información, al webactor, que participa activamente en la construcción del propio contenido existente en "la nube", al introducir él mismo información en el lugar de internet que frecuenta. Ello era, en gran medida, el resultado de un proceso que los estudiosos de la web conocen bien, uno de cuyos puntos de arranque fue el peer to peer, con lo que la web se estaba convirtiendo en una plataforma de intercambio.

También contribuyeron a este avance las IPA (API en inglés: Apliccation Programing Interfaces), que son entradas que los diseñadores de un programa ponen voluntariamente a disposición de los usuarios/creadores para que utilicen los elementos que les convenga. Esta puerta trasera en los programas posibilitó los mashup. Su nacimiento nos ilustra sobre las posibilidades que se estaban generando, entre otras cosas, para las web del delito:

Según el editor y bloguero Tim O’Reilly debemos la primera de estas aplicaciones al desarrollador de programas Paul Rademacher, con su servicio Housing-Maps.com creado a comienzos de 2005.

Al igual que millones de personas en Silicon Valley y la región de San Francisco, Rademacher estaba buscando un apartamento nuevo y utilizó el sitio de anuncios de Craiglist. Frustrado por no poder asociar una mapa geográfico con los anuncios que le interesaban, desarrolló una aplicación que mezcla (mash up, en inglés) automáticamente las listas de Craiglist y la aplicación de localización de Google maps (Pisani y Piotet, 2009: 86)

Este nuevo sistema abría unas posibilidades enormes que pronto encontraron aplicación en las web del delito, puesto que permitía incorporar datos y señalar lugares sobre aplicaciones ya existentes, como Google Maps. De hecho el Chicago Crime.org se suele citar como ejemplo de mashup.
Los flujos RSS, que desde un sitio se envían al usuario interesado, o los mensajes a los Smart Phone, son otras prestaciones que forman parte de la vida cotidiana de los usuarios de las TIC que, junto con las redes sociales, ya se están introduciendo en los lugares web que nos ocupan, lo cual, probablemente, multiplicará su capacidad y su influencia sobre el quehacer diario de las personas.

Seguramente se podrían rastrear otras innovaciones en la red que acrecentarán en un corto lapso las potencialidades de estas web participativas y que hoy ya están contribuyendo a modelar su futuro. Pero, para el análisis que realizamos en este artículo, es más importante señalar el despegue de la web 2.0, su éxito y los factores que lo han hecho posible.

Probablemente, una de las razones de su expansión fue su apropiación por parte de los jóvenes, que abarca desde las redes sociales hasta los sistemas de intercambio de archivos variopintos, por poner dos ejemplos. Este fenómeno, a su vez, podría estar relacionado, entre otras cosas, con la escasez de espacios de encuentro de las urbes norteamericanas, como ha señalado la antropóloga Danah Boyd ${ }^{10}$.

Es significativo que factores territoriales estén en la base del desarrollo de ciertos lugares en la red y que el progreso de estos repercuta, a su vez, en los comportamientos espaciales de los individuos, a la par que promueve un nuevo modelo de vínculos personales que ha dado en denominarse "individualismo reticular":

Mientras que las relaciones de antaño estaban principalmente determinadas por los lugares (la aldea, el barrio, la Ilamada desde un teléfono fijo a otro, por ejemplo), internet y la telefonía móvil privilegian las relaciones de persona a persona y los grupos flexibles. En vez de depender de una sola comunidad, primero local, tendemos cada vez más a conectarnos a una gran variedad de redes menos densas y más dispersas geográficamente. (Pisani y Piotet, 2009: 60)

\footnotetext{
10 Entrevistada por Pisani y Piotet. Pisani y Piotet (2009: 46-49). También es interesante su blog www. zephoria.org
} 
También la simplificación y la aparente desaparición de la tecnología han contribuido de manera importante a su éxito. Moverse en Facebook o My Space es fácil. Quizás uno de los mejores ejemplos de esta aparente sencillez es Google, pues la compleja trama de algoritmos que posibilita sus búsquedas se esconde tras una sencilla ventana rectangular, en una página casi en blanco.

\section{¿Es imparable la expansión de la web 2.0?}

Para poder detectar el peso que tienen las web del delito, así como las perspectivas que se abren para un futuro inmediato, es importante tratar de responder a la pregunta que encabeza este epígrafe o, al menos, analizar los argumentos que se esgrimen para pronosticar su implantación creciente, así como las críticas que tal posibilidad suscita. Aunque cabría establecer matices significativos, los razonamientos, básicamente, van en dos direcciones.

Por un lado, su expansión estriba en que esta web participativa tiene una gran potencialidad económica, puesto que sirve, entre otras cosas, para traspasar al pretendido usuario/consumidor una parte muy importante de las tareas que es preciso realizar para obtener el producto final. Todos conocemos ejemplos en este sentido. Compañías como Easy-jet o Ryanair podrían ser una buena muestra, ya que el futuro viajero reserva por internet el billete, lo imprime en su casa y hace el check-in en un terminal electrónico habilitado a tal efecto. Pero las cosas pueden ir más lejos. Nike, en Second Life, tiene una isla en la que invita al visitante a diseñar sus zapatillas deportivas, que posteriormente recibirá en su domicilio. Probablemente, la clave del asunto no esté solo en que el usuario asume una parte importante de la producción sino que, además, esta es una ventana privilegiada para la empresa, desde la que puede contemplar gustos y tendencias.

Las posibilidades que abre la web 2.0 hacen que esté cada vez más imbricada en la economía global, hasta el punto que se ha acuñado un término para definir esta nueva lógica: wikinomics (Tapscott \& Williams, 2006). Pero, además, tal tendencia está dando síntomas de radicalización: es lo que se conoce como crowdsourcing (Pisani y Piotet,
2009: 197), que consiste en proponer a una gran cantidad de webactores que participen en la realización de ciertas tareas que antes se acometían en el seno de algún tipo de organización. El caso de wikipedia puede ilustrar bien este modelo productivo.

El progreso y la viabilidad de tal procedimiento están por verse, pero lo que parece innegable es que está en alza una nueva manera de actuar en algunos campos, en los que se está poniendo en marcha una economía basada en la interrelación, lo que transforma profundamente los patrones tradicionales. Las web del delito están estrechamente emparentadas con tales tendencias $y$, por tanto, en la medida en que se avance hacia esa participación colectiva en la generación de contenidos, la cartografía de esta clase de hechos se irá percibiendo como algo normal, por su imbricación en la dinámica global y, en consecuencia, como algo legítimo y propio de los tiempos que nos ha tocado vivir.

Ya hemos hecho referencia a la lógica actuarial, que propone como línea estratégica básica la gestión de los riesgos y, desde tal perspectiva, la cartografía que nos ocupa es contemplada como una herramienta de la mayor utilidad, pues serviría para afinar planes de vigilancia, represión o actuaciones policiales. Pero, además, siguiendo la lógica del seguro, se propugna una cierta transferencia de la responsabilidad al potencial beneficiario de la póliza quien, para serlo, ha de cumplir con una serie de requisitos (Fraile et al., 2010: 22-26).

Nos encontramos, por tanto, frente a discursos diferenciados pero que avanzan paralelos, reforzando así una tendencia que parece cada día más consolidada e imparable. Por un lado aflora una dinámica económica, en la que una supuesta cooperación es susceptible de generar valor, por otro, igual que la cooperación por medio de la web incrementa o produce valor, la denuncia colectiva, realizada por el mismo medio y materializada cartográficamente, se presenta como creadora de condiciones de mayor seguridad.

Tal como hemos dicho, los argumentos esgrimidos para mostrar una web 2.0 imparable, en progreso y abriendo caminos que en breve darán pie a otras versiones con ma- 
yores capacidades, van en dos direcciones. La primera es la que acabamos de describir, pero hay también una segunda línea de razonamiento, estrechamente relacionada con esta, aunque quizás va un poco más allá en sus aseveraciones. Es la que se ocupa de lo que se ha dado en Ilamar los "sistemas emergentes" que, en resumen, es aquel discurso que hace referencia a la posibilidad de consolidar una especie de inteligencia colectiva por medio de la participación, posible gracias a la web y a internet, como expondremos a continuación.

Steven Johnson (2003) recurre, para explicarlo, a los ejemplos del "moho del barro" o de las hormigas, entre otros, para mostrar unas estructuras que, desde su punto de vista, son aplicables, en muchos aspectos, al desarrollo de algún software, a la configuración de las ciudades o al funcionamiento neuronal. La idea es relativamente simple: hay sistemas en los que, a partir de reglas elementales, se llega a conductas complejas, tal como sucede, por ejemplo, en un hormiguero. En este, cada uno de sus componentes tiene registrada una orden que le impele a cambiar de función, por ejemplo de obrera a soldado, según el número de compañeras, empleadas en una determinada tarea, que se cruzan en su camino. De este modo, ninguna de las hormigas asume el cometido de organizar el conjunto, de ahí la desmitificación del papel de la reina, pero a partir de la instrucción del cambio de oficio, el hormiguero se equilibra, de forma dinámica, en el punto óptimo. Tal como decíamos, siguiendo reglas sencillas se obtienen comportamientos complejos y esto es lo que recibe el nombre de "sistema emergente" $^{\prime \prime}$ Tendencias de este tipo hace tiempo que empezaron a manifestarse en la red (Johnson, 2003: 109) ${ }^{11}$.

Un factor clave para el funcionamiento de un sistema emergente, y por tanto descentralizado, es la retroalimentación, es decir, que la información que genera revierta a sí mismo en ciclos sucesivos. Los cambios de oficio en el hormiguero obedecen a los encuentros de cada individuo pero, gracias a la retroalimentación, el conjunto se reorganiza, se equilibra

${ }^{11}$ Alexa es un buen ejemplo de ello. y se adapta a las condiciones cambiantes constantemente. Para referirse a este fenómeno en internet, Johnson recurre al ejemplo de la plataforma Slashdot, donde se podía hablar $\mathrm{u}$ opinar sobre casi todo, de manera que en su éxito se escondía su muerte, pues el exceso de ruido la acabaría haciendo inoperante e inútil. El procedimiento que se puso en marcha para evitarlo está en la base del sistema de puntuación que ahora conocemos en casi cualquier web, que permite a los usuarios calificar su contenido jerarquizándolo, función que se incrementa al ser posible opinar sobre él o difundirlo.

Tal dinámica, que ya se ha convertido en cotidiana en la red, encierra un peligro obvio, que es amplificar la opinión o los gustos de la mayoría silenciando o marginando, en consecuencia, los de las minorías. Aunque también es cierto que ya se han diseñado formas de contrarrestar este efecto, no vale la pena detenerse en ellas, pues en las web del delito es la primera tendencia la que tiene mayor peso.

Pensemos esta retroalimentación desde una perspectiva geográfica. La relación de cada uno con el espacio condiciona la información que coloca (o deja de colocar) en la web, lo que, a su vez, influye en el comportamiento espacial del conjunto que, a su vez, introduce más información sobre el mapa de delitos y así sucesivamente. Es cierto que para que esta dinámica funcione es necesaria una masa crítica por debajo de la cual el sistema se colapsaría pero, alcanzada esta, los efectos pueden ser demoledores.

A la vista de este panorama general, parece bastante claro que la web 2.0, y las versiones que la sigan, están Ilamadas a ocupar un lugar muy importante en nuestra vida cotidiana y a influir de manera notable en nuestras actuaciones espaciales. Johnson, al referirse a estos sistemas complejos y a su presencia en nuestras vidas dice:

"A medida que nuestra vida cotidiana se va poblando de emergencia artificial, confiaremos cada vez más en la lógica de estos sistemas, tanto en la Norteamérica corporativa, donde la 'inteligencia de abajo arriba' ha comenzado a sustituir a la 'gestión de calidad' como mantra de moda, como en los movimientos radicales 
de protesta antiglobalización, que modelan explícitamente sus organizaciones sin marcapasos y de forma distribuida". (Johnson, 2003: 61)

Esta reflexión, que nos presenta el lado positivo de los sistemas emergentes, puede hacernos pensar además en los peligros de esa influencia creciente de que nos habla. Otros también se han referido a la dictadura de las mayorías o a la entronización del aficionado que conllevan estos lugares web. Riesgo que se acrecienta cuando la información gira en torno a la peligrosidad del espacio y a la percepción de seguridad, pero sobre este asunto volveremos al final de estas páginas.

\section{La web del delito en Iberoamérica}

Partiendo, por tanto, de la idea de que Internet, las $\operatorname{TIC} y$, en concreto, la Web 2.0, así como las versiones que le seguirán, tiene una influencia considerable, tanto a nivel macroeconómico y supranacional como en la vida cotidiana y en nuestro entorno más próximo, parece imprescindible acometer un análisis minucioso de estos lugares en la red, donde se cartografían delitos o conflictos, configurando así la percepción del medio en que nos movemos. Tal como anunciamos al comienzo, el objetivo de estas páginas es estudiar el caso de lberoamérica, situándolo en el contexto general que ya hemos descrito, a sabiendas de que lo que ocurre en aquellos países a que nos referiremos obedece a esas dinámicas globales.

Tampoco debemos olvidar que la seguridad es un tema que preocupa a la ciudadanía. Según los datos del informe de 2010 del Latinobarómetro la delincuencia y la seguridad pública eran los problemas más importantes del país en Venezuela $(64 \%$ de respuestas), Argentina (37\%), México (35\%), y Chile $(22 \%)$. En Colombia era más relevante el desempleo (31\%), mientras que la seguridad lo era para un 14\%. En Brasil estaba en cabeza la salud con un $28 \%$ de respuestas, mientras que la seguridad obtenía un $10 \%$. En Ecuador la economía pasa al primer lugar
(57\%), mientras la seguridad ocupa el segundo con un 24\% (Corporación Latinobarómetro, 2010: 16-17).

Para comprender en profundidad el fenómeno que nos ocupa será imprescindible contextualizarlo desde dos ópticas diferentes. Por un lado atenderemos a la implantación diferenciada de las TIC, ya sea a nivel nacional en los países de referencia o a la divergencia entre el ámbito rural y el urbano. Por otro, analizaremos algunas variables de carácter social, político o económico que enmarcarán, y ayudarán a entender, la expansión de este tipo de cartografía y las estrategias que la impulsan. Para ello estudiaremos una serie de índices, como los niveles de renta o educativos, los referidos al grado de satisfacción o de garantías políticas, así como algunos indicadores relativos a los niveles de seguridad. Estos elementos no son los causantes del progreso de estos sitios web que, como hemos dicho, obedecen a dinámicas globales, pero sí explican una parte importante de las diferencias regionales.

Tal como hemos avanzado, nos centraremos en los siete países (Argentina, Brasil, Chile, Colombia, Ecuador, México y Venezuela) que tenían, a finales de 2010, un total de dieciocho páginas de este tipo, entre todos ellos. En algunos de los cuadros en los que se resume la información señalada incluiremos España, como punto de referencia, para facilitar las comparaciones. Dejamos por tanto fuera del estudio aquellos países que en aquella fecha no contaban con ninguna website como las analizadas.

El objetivo último es encontrar algunas regularidades en el funcionamiento de este fenómeno para poder explicarlo y esbozar propuestas que podrían guiar una cierta intervención al respecto.

\section{El grado de implantación de las TIC en Latinoamérica}

Los países latinoamericanos presentan disparidades notables en cuanto a su situación política, económica y social y, además, respecto al despliegue de las TIC, con bre- 
Cuadro $\mathrm{N}^{\circ} 1$

Grado de penetración de las TIC

\begin{tabular}{|l|r|r|r|r|r|r|r|r|}
\hline & Argentina & Brasil & Chile & Colombia & Ecuador & México & Venezuela & España \\
\hline $\begin{array}{l}\text { Networked Readi- } \\
\text { ness Index 2009- } \\
2010^{(1)}\end{array}$ & 3,38 & 3,80 & 4,13 & 3,80 & 3,04 & 3,61 & 3,06 & 4,37 \\
\hline $\begin{array}{l}\text { Networked Readi- } \\
\text { ness Index 2007- } \\
2008 \text { (1) }^{-1}\end{array}$ & 3,59 & 3,87 & 4,35 & 3,71 & 3,09 & 3,90 & 3,44 & 4,47 \\
\hline $\begin{array}{l}\text { Usuarios de internet } \\
\text { (\% de la población) }\end{array}$ & 28,11 & 37,52 & 32,47 & 38,5 & 28,80 & 21,71 & 25,49 & 56,74 \\
\hline $\begin{array}{l}\text { Disponibilidad de } \\
\text { las últimas tecnolo- } \\
\text { gías (1) (entre 1 y 7) }\end{array}$ & 4,41 & 5,29 & 5,75 & 4,22 & 3,66 & 4,58 & 3,89 & 5,47 \\
\hline $\begin{array}{l}\text { Accesibilidad del } \\
\text { contenido digital (1) } \\
\text { (entre 1 y 7) }\end{array}$ & 4,77 & 4,86 & 5,58 & 4,59 & 3,69 & 4,53 & 4,51 & 5,42 \\
\hline $\begin{array}{l}\text { Tarifas de banda } \\
\text { ancha fija (2) (3) }\end{array}$ & 76,66 & 56,5 & 67,24 & 59,88 & 89,11 & 53,61 & 45,83 & 25,43 \\
\hline $\begin{array}{l}\text { Ordenadores perso- } \\
\text { nales por 100 habi- } \\
\text { tantes (2) }\end{array}$ & 9,04 & 16,12 & 14,11 & 11,25 & 12,95 & 14,10 & 9,26 & 40,04 \\
\hline $\begin{array}{l}\text { Suscriptores de ban- } \\
\text { da ancha por 100 } \\
\text { habitantes (2) }\end{array}$ & 7,99 & 5,26 & 8,49 & 4,23 & 0,26 & 7,00 & 4,73 & 20,22 \\
\hline
\end{tabular}

Fuente: Elaboración Propia a partir de (1): World Economic Forum, Executive Opinion Survey 2008, 2009. (2) International Telecommunication Union, Measuring the Information Society 2009. (3) Precio mensual por residencia en US\$ (a valores de PPA).

chas importantes entre algunos de ellos ${ }^{12}$. Por eso, antes de adentrarnos en el estudio de esta cartografía electrónica, es necesario conocer su grado de implantación, lo cual nos dará una información muy valiosa para entender las diferencias en la aparición de tales mapas.

Los líderes en la implantación de las TIC han sido los países industrializados y existen, en general, notables diferencias entre estos y los que nos ocupan. Siguiendo la dinámica mundial de expansión generalizada de estas,

12 Desde la última década del siglo XX se utiliza el concepto de brecha digital (digital divide en la expresión original en inglés) para referirse, de manera muy resumida, a la fractura existente entre lo que se podría considerar el usuario estándar de la tecnología digital y quien no lo es.
Latinoamérica ha presentado en los últimos años un crecimiento sostenido del índice de desarrollo de las TIC (Manievicz, 2009: 41) (ICT Development Index) ${ }^{13}$, a pesar de ello, parece que se estancó o entró en una tendencia a la baja, en 2010, si tenemos en cuenta otros indicadores como el Networked Readiness Index ${ }^{14}$ (Cuadro $N^{\circ} 1$ ) o el Indicador

13 El ICT Development Index (IDI) es uno de los índices de referencia para la medida del desarrollo de la sociedad de la información en un país. Lo publica anualmente la agencia de las Naciones Unidas conocida como International Telecomunications Union, está compuesto por tres subíndices relativos al acceso a las TIC, a su uso y a las habilidades necesarias para ello.

14 El Networked Readiness Index (NRI), publicado anualmente por el World Economic Forum, es algo más complejo que el IDI, puesto que tiene en cuenta hasta 68 variables, mientras que el IDI solamente 
de la Sociedad de la Información ${ }^{15}$, pero en 2011 ya había comenzado la recuperación. En términos generales, Latinoamérica ha experimentado el mayor incremento de usuarios de internet a escala mundial, que han crecido un $23 \%$ entre 2009 y 2010 , lo que representa un $8 \%$ del total global (ComScore, 2010). Estas cifras, que sin duda son muy halagüeñas, esconden una realidad mucho más compleja, que se hace visible cuando cambiamos de escala y nos centramos en cada uno de los países. El índice por subregiones nos muestra que hay zonas que están mucho más avanzadas que otras. El Cono Sur y el Caribe son las más desarrolladas, con índices que representan valores de alrededor del $60 \%$ del que tienen en conjunto los países de la OCDE. Le sigue la subregión andina, con tasas que rozan el $50 \%$ de las de la OCDE, y Centroamérica que no llega al 25\% (Cimoli, 2010: 15).

En general, podemos decir que en la mayoría de países latinoamericanos el número de usuarios ha crecido de una manera tan notoria gracias, entre otras cosas, a la proliferación de instalaciones de acceso público, ya sean privadas o comunitarias (Manievicz, 2009: 27 ss.), lo que nos indica que en algunos de ellos su implantación en el hogar está bastante lejos de ser una realidad. Cuando comparamos, en el interior de cada uno, el uso doméstico de internet en las zonas urbanas y en las rurales la brecha se amplía considerablemente. Los datos (Cuadro $\mathrm{N}^{\circ}$ 2) nos muestran que se trata de un fenómeno eminentemente urbano, lo que se acrecienta cuando nos fijamos en los hogares, en este

contempla 11, de las cuales 7 se encuentran en el $\mathrm{NRI}$, por lo que podemos afirmar que el IDI está parcialmente incluido en el NRI. Además, el NRI reviste un interés especial puesto que algunos de los indicadores que utiliza tienen relación con las libertades políticas de los países estudiados. Se puede encontrar una explicación en profundidad sobre la medición de la TIC en el mundo en Crespi, 2010.

15 El Indicador de la Sociedad de la Información es otro índice creado por la empresa Everis y por CELA-IESE Business School para medir el avance de la sociedad de la información en Latinoamérica. Según su informe de mayo de 2010, ver Iglesias, 2010: 1015, la sociedad de la información está experimentando en los últimos tiempos un cierto estancamiento relacionado con la crisis, aunque durante el 2011 ha repuntado, ver Pin, 2011: 10-13. sentido, los datos obtenidos son bastante homogéneos en el ámbito estudiado ${ }^{16}$.

Las diferencias entre ellos se hacen patentes al contemplar el porcentaje de internet en el hogar dentro de cada categoría, rural o urbana (porcentaje de hogares de la zona). En este caso Brasil encabeza el ranking, seguido de Chile y Colombia, dejando a Ecuador en la cola. Otro tema interesante es la implantación de la banda ancha, en la que destacan Chile, Argentina y México.

\section{Algunos indicadores que contextualizan la aparición de las páginas web del delito}

El nivel de implantación de las TIC que resumimos en el Cuadro $\mathrm{N}^{\circ} 1$, sin duda, es un factor importante para entender las diferencias regionales en la expansión de la web del delito, pero, tal como dijimos, hay otros elementos que contribuyen a explicar esta marcada diversidad, pues Argentina cuenta con nueve de las dieciocho páginas, un 50\% por tanto, que la sitúa a la cabeza con una diferencia considerable respecto a los demás. Le siguen Brasil con tres $(16,66 \%)$, Chile con dos $(11,11 \%)$ y Colombia, Ecuador, México y Venezuela con una $(5,55 \%)$ cada uno (Cuadro № 3 ).

Pero la preeminencia de Argentina no obedece, en principio, al hecho de tener una ventaja comparativa sobre los otros en el grado de penetración de las TIC, aunque encabeza con Chile el ranking de suscriptores de banda ancha de toda la región, pero cuenta con la desventaja de tener el precio más caro de los países estudiados.

Algunos trabajos explican la relación directamente proporcional entre nivel de estudios, clase social y uso de internet (Bouza, 2003). Si tenemos en cuenta los indicadores relativos al nivel educativo de la población por países (Cuadro $N^{\circ} 4$ ), vemos que Argentina destaca de manera ostensible en la ratio de matriculados en estudios universitarios. En las otras variables elegidas ${ }^{17}$, como la calidad

\footnotetext{
16 No hemos obtenido datos sobre este asunto de Argentina, México y Venezuela, y los datos de Colombia están incompletos. Véase el Cuadro $N^{\circ} 2$.

17 Estas variables no pretenden ser exhaustivas ni del todo representativas de la sociedad, economía o
} 
Cuadro $\mathrm{N}^{\circ} 2$

Territorialidad del uso de las TIC

\begin{tabular}{|l|r|r|r|r|r|r|r|r|}
\hline & Argentina & Brasil & Chile & Colombia & Ecuador & México & Venezuela & España \\
\hline $\begin{array}{l}\text { Usuarios de internet en } \\
\text { zonas } \\
\text { Urbanas } \\
\text { (\% del total de usuarios) }\end{array}$ & SD & 95,6 & 94,2 & SD & 87,7 & SD & SD & SD \\
\hline $\begin{array}{l}\text { Usuarios de internet en } \\
\text { zonas rurales } \\
\text { (\% del total de usuarios) }\end{array}$ & SD & 4,4 & 5,8 & SD & 12,3 & SD & SD & SD \\
\hline $\begin{array}{l}\text { Internet en el hogar en } \\
\text { zonas urbanas (\% del total } \\
\text { de hogares) }\end{array}$ & SD & 97,9 & 98,1 & 98,1 & 97,6 & SD & SD & 82,4 \\
\hline $\begin{array}{l}\text { Internet en el hogar en } \\
\text { zonas rurales } \\
\text { (\% del total de hogares) }\end{array}$ & SD & 2,1 & 1,9 & 1,9 & 2,4 & SD & SD & 17,6 \\
\hline $\begin{array}{l}\text { Internet en el hogar en zo- } \\
\text { nas urbanas (\% de hogares } \\
\text { de la zona) }\end{array}$ & SD & 27,2 & 21,6 & 21,6 & 10,7 & SD & SD & 71,6 \\
\hline $\begin{array}{l}\text { Internet en el hogar en } \\
\text { zonas rurales } \\
\text { (\% de hogares de la zona) }\end{array}$ & SD & 3,3 & 2,8 & 2,8 & 0,6 & SD & SD & 47,3 \\
\hline
\end{tabular}

Fuente: Elaboración propia a partir de: Argentina: International Telecomunications Union, 2009; Brasil: Pesquisa Nacional por Amostra Domicilios, 2008; Chile: Encuesta CASEN, 2006; Colombia: Gran Encuesta Integrada de Hogares, 2007; Ecuador: Encuesta de Empleo, 2009; México: Encuesta Nacional sobre Disponibilidad y Uso de las TIC, 2009; Venezuela: Encuesta de Hogares por Muestreo, 2007; España: Encuesta sobre Equipamiento y Uso de Tecnologías de la Información y Comunicación en los Hogares, 2010. (SD: sin datos).

Cuadro $\mathrm{N}^{\circ} 3$

Distribución de las web del delito por países

\begin{tabular}{|l|c|c|c|c|c|c|c|}
\hline & Argentina & Brasil & Chile & Colombia & Ecuador & México & Venezuela \\
\hline Número de páginas publicadas & 9 & 3 & 2 & 1 & 1 & 1 & 1 \\
\hline
\end{tabular}

Fuente: Elaboración propia.

del sistema educativo, el gasto en educación o el porcentaje de enrolados en la educación

garantías políticas de los países que estamos estu diando, sino dar una idea de lo que en ellos está ocurriendo, por eso utilizamos algunos de los indicadores que conforman el Networked Readiness Index del World Economic Forum y el Human Development Index del United Nations Development Programme. secundaria, ocupa también los primeros lugares de la lista.

En lo que respecta a la satisfacción y las garantías políticas (Cuadro $N^{\circ} 5$ ), está demostrado que existe un vínculo entre la confianza en las instituciones y el aumento de la sensación de seguridad de la ciudadanía (Dammert, 2005: 14; Dammert y Malone, 2002). Brasil es el país de la muestra en el que se está más satisfecho con la libertad individual 
Cuadro $\mathrm{N}^{\circ} 4$

Indicadores sobre educación

\begin{tabular}{|l|r|r|r|r|r|r|r|r|}
\hline & Argentina & Brasil & Chile & Colombia & Ecuador & México & Venezuela & España \\
\hline $\begin{array}{l}\text { Calidad del sistema educativo } \\
\text { (1) (1-7) }\end{array}$ & 3,13 & 3,01 & 2,97 & 3,50 & 2,59 & 2,80 & 2,67 & 3,38 \\
\hline Gasto en educación (2) (\% PIB) & 3,98 & 4,44 & 3,37 & 4,82 & 1,38 & 5,47 & 3,38 & 3,92 \\
\hline $\begin{array}{l}\text { Tasa neta de matriculación en } \\
\text { educación secundaria (\% de } \\
\text { población en edad de cursar } \\
\text { secundaria) (3) }\end{array}$ & 79,4 & 77 & 85,3 & 71,2 & 59,2 & 70,9 & 69,5 & 94,3 \\
\hline $\begin{array}{l}\text { Tasa bruta de matriculación } \\
\text { en educación terciaria (\% de } \\
\text { población en edad de cursar } \\
\text { terciaria) (3) }\end{array}$ & 68,1 & 30 & 52,1 & 35,4 & 35,3 & 26,3 & 78,1 & 68,5 \\
\hline
\end{tabular}

Fuente: Elaboración propia a partir de (1): The World Bank, World Development Indicators Online (2009); fuentes nacionales. (2): The World Bank, World Development Indicators Online (2009); fuentes nacionales. (3): United Nations Development Programme, Human Development Report 2010.

\section{Cuadro $\mathrm{N}^{\circ} 5$}

Indicadores sobre satisfacción y garantías políticas

\begin{tabular}{|l|r|r|r|r|r|r|r|r|}
\hline & Argentina & Brasil & Chile & Colombia & Ecuador & México & Venezuela & España \\
\hline $\begin{array}{l}\text { Satisfacción con la libertad de } \\
\text { elección (\%) (1) }\end{array}$ & 62 & 76 & 72 & 75 & 73 & 66 & 65 & 70 \\
\hline Libertad de prensa (0-100) (1) & 11,3 & 15,9 & 10,5 & 40,1 & 20 & 48,3 & 39,5 & 11 \\
\hline $\begin{array}{l}\text { Efectividad de los cuerpos legis- } \\
\text { lativos (1-7) (2) }\end{array}$ & 2,04 & 2,32 & 3,63 & 3,00 & 3,66 & 2,64 & 1,52 & 3,85 \\
\hline $\begin{array}{l}\text { Víctimas de corrupción (\% de } \\
\text { personas que se enfrentaron a } \\
\text { una situación de soborno en el } \\
\text { último año) (1) }\end{array}$ & 8 & 5 & 8 & 11 & 7 & 11 & & 7 \\
\hline $\begin{array}{l}\text { Participación política (\% de per- } \\
\text { sonas que manifestaron su opi- } \\
\text { nión a funcionarios públicos) (1) }\end{array}$ & 11 & 19 & 26 & 9 & 15 & 22 & & 6 \\
\hline
\end{tabular}

Fuente: Elaboración propia a partir de los datos de (1): United Nations Development Programme, Human Development Report 2010. (2): World Economic Forum, Executive Opinion Survey 2008, 2009, 2010.

de elección ${ }^{18}$ y Argentina el que se encuentra en la cola. En lo que se refiere a la libertad de

\footnotetext{
${ }^{18}$ Se trata de la libertad que los individuos disfrutan en su vida. Parece que esta no tiene una correspondencia directa con la democracia a nivel nacional. Ver United Nations Development Programme (2010: 76-79).
}

prensa, ambos tienen un buen coeficiente y Venezuela, Colombia y México son los peor situados. En lo tocante a la efectividad de los cuerpos legislativos, destacan Ecuador y Chile y ocupan los lugares más bajos Venezuela, Argentina y Brasil respectivamente. México y Colombia son los líderes en corrupción, les siguen Argentina y Chile. En cambio este último es el país en el que se da una parti- 
Cuadro $\mathrm{N}^{\circ} 6$

Indicadores económicos y de empleo

\begin{tabular}{|c|c|c|c|c|c|c|c|c|}
\hline & Argentina & Brasil & Chile & Colombia & Ecuador & México & Venezuela & España \\
\hline $\begin{array}{l}\text { Ingreso nacional bruto } \\
\text { (INB) per cápita (PPA en } \\
\text { US\$ de 2008) }\end{array}$ & 14.603 & 10.607 & 13.561 & 8.589 & 7.931 & 13.971 & 11.846 & 29.661 \\
\hline $\begin{array}{l}\text { Desigualdad (Coeficiente } \\
\text { de Gini, Ingresos) (0-100) }\end{array}$ & 48,8 & 55,0 & 52,0 & 58,5 & 54,4 & 48,1 & 43,4 & 34,7 \\
\hline $\begin{array}{l}\text { Empleo formal (\% del } \\
\text { empleo total) }(1)\end{array}$ & 79,9 & 68,1 & 75,2 & 58,9 & 66,2 & 70,5 & 63,5 & 88,1 \\
\hline $\begin{array}{l}\text { Empleo vulnerable (\% del } \\
\text { empleo total) }{ }^{(1)}\end{array}$ & 20,1 & 27,2 & 24,8 & 40,9 & 33,8 & 29,5 & 29,8 & 11,8 \\
\hline Tasa de desempleo (2010) & $7,5^{(2)}$ & $5,7^{(3)}$ & $8,1^{(4)}$ & $11,8^{(5)}$ & $5^{(6)}$ & $4,8^{(7)}$ & $7,5^{(8)}$ & $20,33^{(9)}$ \\
\hline
\end{tabular}

Fuente: Elaboración propia a partir de los datos de (1): United Nations Development Programme, Human Development Report 2010. (2): World Economic Forum, Executive Opinion Survey 2008, 2009, 2010. (2): INDEC Argentina. (3): IBGE Brasil (4): INE Chile; (5) DANE Colombia. (6): SENPLADES Ecuador. (7): INEGI México. (8) INE Venezuela (2009). (9) INE España.

cipación política más elevada, seguido por México y Venezuela, y quedando Argentina en última posición.

En cuanto a los indicadores económicos (Cuadro $N^{\circ} 6$ ), algunos estudios señalan que el aumento de la delincuencia tiene menos que ver con las tasas de desempleo o de pobreza que con la de desigualdad (Dammert, 2005: 14-16). De todos modos, consideramos que la pobreza, el desempleo o la precariedad laboral, aumentan la sensación de vulnerabilidad de la ciudadanía y, por ende, de inseguridad. Argentina destaca en Ingreso Nacional Bruto per cápita, seguida por México y Chile y obtiene el tercer puesto entre los que tienen una menor desigualdad en cuanto a ingresos, tras Venezuela y México. Los países más polarizados en este sentido son Colombia, Ecuador y Brasil, respectivamente. En lo que se refiere al empleo, Argentina tiene el mayor porcentaje de empleo formal seguida por Chile y México. En la cola encontramos a Ecuador y Venezuela. Ecuador, sin embargo, disfruta de la menor tasa de desempleo de los países estudiados siendo Colombia la que tiene la mayor.

Finalmente, en relación con la seguridad, los datos (Cuadro $N^{\circ} 7$ ) muestran que Colombia tiene el índice más alto de homi- cidios y Argentina el más bajo. Esta tiene, sin embargo, la tasa de robos más elevada de los países estudiados de los que disponemos de información, le sigue Chile muy por detrás. Ecuador, y Argentina a la zaga, despuntan en victimización por asalto. Venezuela es el país donde la percepción de seguridad es más baja, seguida por Ecuador y Argentina. Es en Colombia donde encontramos la más alta.

En resumen, si tomamos Argentina como referencia para obtener una imagen de conjunto, por ser el país con el mayor número de páginas de este tipo, vemos que el factor tecnológico es importante, pero no definitivo, pues tiene una nota relativamente baja en el NRI y no sobresale en el número de usuarios de internet o en la cantidad de equipamiento informático, pero es el lugar con un mayor porcentaje de suscriptores de banda ancha justo por detrás de Chile, lo que nos hace suponer que, al menos en los hogares urbanos, su uso debe ser intensivo en comparación con los países del área.

Por otro lado, Argentina cuenta con uno los niveles educativos más altos, quedando por detrás de Venezuela y por delante de Chile. También destaca positivamente en Ingreso Nacional Bruto per cápita y tiene, además, uno de los menores coeficientes de desigual- 
Cuadro $\mathrm{N}^{\circ} 7$

Indicadores sobre seguridad

\begin{tabular}{|l|r|r|r|r|r|r|r|r|}
\hline & Argentina & Brasil & Chile & Colombia & Ecuador & México & Venezuela & España \\
\hline $\begin{array}{l}\text { Tasa de homicidios (por cada } \\
100.000 \text { personas) }\end{array}$ & 5,2 & 22 & 8,1 & 38,8 & 18,1 & 11,6 & 52 & 0,9 \\
\hline $\begin{array}{l}\text { Tasa de robos (por cada 100.000 } \\
\text { personas) }\end{array}$ & 859 & $\mathrm{sd}$ & 180 & $\mathrm{sd}$ & 399 & 505 & $\mathrm{sd}$ & 1.067 \\
\hline $\begin{array}{l}\text { Víctimas de asalto (\% que infor- } \\
\text { ma haber sido víctima) }\end{array}$ & 16 & 10 & 13 & 13 & 20 & 12 & 11 & 6 \\
\hline Percepción de seguridad (\%) & 39 & 40 & 42 & 45 & 38 & 44 & 23 & 58 \\
\hline
\end{tabular}

Fuente: Elaboración propia a partir de United Nations Development Programme, Human Development Report 2010.

dad respecto a los ingresos, quedando cinco puntos por detrás del líder, Venezuela, y a siete décimas de México. Asimismo, cuenta con la tasa más alta de empleo, pero es el país menos satisfecho del grupo en lo tocante a libertad de elección política y comparte con Chile el tercer puesto en victimización por corrupción. A pesar de ello tiene una libertad de prensa aceptable y una participación política, entendida como reclamaciones ante la administración, floja. En el apartado de seguridad tiene la menor tasa de homicidios, aunque la más alta de robos, entre aquellos de los que tenemos información, y la segunda de asaltos. La percepción de seguridad es la más baja de todo el grupo.

Esto plantea la pregunta de por qué en Chile han aparecido solamente dos sitios web con cartografía online del delito y tres en Brasil. Los datos muestran cómo la tecnología, a partir de cierto umbral ${ }^{19}$, no es el factor determinante. En otros ámbitos, como la educación, los tres países muestran resultados parecidos salvo en la matriculación en estudios universitarios, en la que Argentina destaca y Brasil queda en tercera posición, por lo que también se podría decir que, rebasado un umbral mínimo, este indicador pierde relevancia. En lo que respecta a los indicadores de pobreza, de calidad del empleo o de desigualdad, nos encontramos con cifras

\footnotetext{
${ }^{19}$ No ahondaremos en esta cuestión ya que no es la intención de este artículo la creación de un índice que responda a este tipo de preguntas.
}

bastante parecidas, por lo que debemos considerar que inciden de manera parecida en la sensación de seguridad.

En cuanto a las garantías y libertades políticas, vemos que existe una correlación inversa, en estos tres países, entre la participación política y el número de páginas aparecidas, como también la hay con la satisfacción en la libertad de elección y la efectividad de los cuerpos legislativos, mientras que la correlación es positiva con la libertad de prensa. Esto indica que estas web surgen en sociedades donde, a pesar de haber un nivel de libertades relativamente alto, existe una percepción contraria y un ambiente político crispado en el que la ciudadanía no confía en recibir una respuesta satisfactoria a sus problemas por parte de la administración.

Finalmente, en lo tocante a la seguridad observamos que hay una correlación positiva entre el surgimiento de esta cartografía y factores como su percepción o el número de robos, lo que significa que esta sensación se construye más a partir de estos que de los asesinatos. Como veremos más adelante, la prensa desempeña en este proceso un papel de la mayor importancia.

Por todo ello, podemos avanzar que la aparición de estas web, cumplido unos estándares mínimos de acceso a las TIC y de formación, está relacionada sobre todo con aquellos elementos que conforman la sensación de seguridad y con los modos de participación política y la percepción de la 
ciudadanía acerca de la efectividad de los cuerpos legislativos a la hora de gestionar y solucionar sus problemas, así como con algunos factores de carácter político que expondremos más adelante.

\section{Análisis de las páginas web del delito}

Tras establecer los elementos que explican y contextualizan la expansión de este tipo de páginas, es posible acometer su análisis, lo que debería hacerse desde una doble perspectiva. En primer lugar nos ocuparemos de su titularidad, forma y contenido para pasar, a continuación, a tratar el clima sociopolítico en el que han surgido. En lo tocante a las fuentes, hemos abordado la tarea desde una doble óptica. En cada uno de los frentes hemos recurrido a las fuentes primarias. En la primera parte utilizaremos, básicamente, los websites que son objeto de este estudio. La segunda la construiremos analizado el discurso que se hace sobre la seguridad desde los propios websites y a través de artículos de la prensa online.

\section{Titularidad, forma y contenido}

Los países punteros en la publicación de mapas online del delito son los anglosajones, con los Estados Unidos a la cabeza (Fraile y Bonastra, 2010) y los principales titulares son los departamentos de policía de diferentes ciudades o agencias gubernamentales relacionadas, de algún modo, con el control de la delincuencia. En estos lugares de capitalismo avanzado hay una cierta tendencia a responsabilizar a los ciudadanos de la tarea de garantizar su seguridad, como consecuencia del adelgazamiento del Estado (Rose, 1999: 145), lo que, en parte, explica el progreso de este tipo de páginas gestionadas por entidades oficiales. Pero este no es el caso de los países que nos ocupan, en los que el porcentaje de sitios web cuyo titular es un organismo público es relativamente bajo. De las dieciocho páginas que funcionaban en 2010 , nueve $(50 \%)$ pertenecían a particulares u ONG, cuatro $(22,2 \%)$ estaban relacionadas directa o indirectamente con políticos electos o en campaña, tres $(16,6 \%)$ con cuerpos públicos de seguridad o entes gubernamentales, una $(5,5 \%)$ con un periódico y una $(5,5 \%)$ con una organización empresarial. Si nos fijamos en Argentina, el país donde este fenómeno es más importante, vemos que la tendencia general se agudiza en beneficio de las correspondientes a políticos electos o en campaña, que tienen la titularidad de tres de ellas $^{20}$ (33,3\% de las argentinas), y los particulares y ONG, con tres más (33'3\%). Las tres restantes quedan repartidas entre un periódico $(11,1 \%)$, una asociación empresarial $(11,1 \%)$ y un gobierno provincial $(11,1 \%)$, el de San Luis.

También es importante saber qué tipo de datos se cartografían y de dónde provienen. En este caso, y habida cuenta de la titularidad de estos mapas, no es de extrañar que en la mayor parte ingresen la información los propios usuarios, esto ocurre en once de las dieciocho páginas $(61,1 \%)$. En dos ocasiones $(11,1 \%)$ encontramos a los usuarios y la prensa como fuente de los datos representados, en otras dos $(11,1 \%)$ solamente a la policía ${ }^{21}$ y, de las tres restantes, una $(5,5 \%)$ los obtiene de la prensa, otra $(5,5 \%)$ de la prensa y de la policía y la otra $(5,5 \%)$ de los usuarios y la policía. Así, se utiliza a los implicados como fuente de información, sea de manera exclusiva o en combinación con las otras, en 14 de las 18 páginas $(77,7 \%)$, por tanto, se rompe, una vez más, la tendencia general observada en el ámbito anglosajón. Habría que considerar, además, la verificación de la información ingresada por estos usuarios, que es bastante limitada. Incluso en Wikicrimes ${ }^{22}$, creada por un grupo de investigadores de la Universidad de Fortaleza y que contempla este aspecto, no hay ninguna garantía de que lo denunciado sea auténtico ${ }^{23}$.

\footnotetext{
20 El "Mapa del delito de la Provincia de Santa Fe" (www.mapadeldelito.info/), puesto en marcha por Alberto Martínez, candidato a diputado provincial por la lista Campo Popular en la provincia de Santa Fe; el Mapa del Delito de Rosario (boasso24horas. com/), promovido por Jorge Boasso, candidato a intendente de Rosario; o el "Mapa de la Inseguridad" (www.mapadelainseguridad.com/), del candidato a diputado provincial por la lista Unión Celeste y Blanco en la Provincia de Buenos Aires.

${ }^{21}$ Se trata de dos páginas brasileñas ligadas a cuerpos policiales: http://geo.defesasocial.mg.gov.br/; y http://www.mapaocorrencias.site40.net/.

$22 \mathrm{http} / / /$ wikicrimes.org/

${ }^{23}$ La validación se hace a través de la confirmación o la negación de los propios usuarios a través de la viñeta emergente relacionada con cada punto. Por
} 
Es conveniente también conocer qué contravenciones se cartografían, pues ello configura una imagen de la realidad que se pretende plasmar. Hemos de considerar que representar todos los delitos tipificados en el código penal de cada país restaría legibilidad a los mapas resultantes, por lo que es necesario simplificar, lo que comporta una selección que orienta el contenido final, de manera que producir una estadística fiable se torna difícil, a tenor de la disparidad de los criterios utilizado en su elección. Así, tenemos dos extremos, por un lado la inclusión de demasiados delitos y, por otro, la consideración de uno solo. En la primera categoría encontramos tres mapas, uno construido con datos policiales y de prensa que obliga a entrar en cada punto para ver de qué delito se trata $^{24}$, uno de Bogotá en el que introducían los datos los usuarios y elegían ellos mismos la clase de delito y los iconos ${ }^{25}$, y otro con la exagerada cifra de treinta y cuatro tipos de contravenciones y una dilatada iconografía ${ }^{26}$. En los tres casos el resultado es bastante confuso, ya sea por exceso de iconos que restan legibilidad al mapa, ya sea por la monotonía de uno solo, que, en último término, provoca una sensación parecida. En el otro extremo hay dos mapas especializados, ambos en homicidios, uno argentino ${ }^{27}$ y otro brasileño ${ }^{28}$, que además de no reflejar los delitos más recurrentes, no hacen sino exacerbar la sensación de inseguridad. Entre estos dos polos, se podría decir que se cartografían aquellos delitos que producen más alarma social, los denominados DMCS (Delitos con Mayor Connotación Social), como robos, robos con arma, venta de drogas, lesiones, homicidio, abuso sexual o violación y secuestro. Pero también en ellos se distorsiona la realidad, dado que en pocas ocasiones se definen con precisión los delitos y se deja al usuario que

el simple hecho de no estar refutada por nadie, en las viñetas aparece un sello que reza: "credibility: high".

${ }^{24}$ El argentino http://www.mapadeldelito.info/

$25 \mathrm{El}$ colombiano

http://maps.google.com $/ \mathrm{maps} / \mathrm{ms}$ ? ie=UTF8\&hl=es \& $\mathrm{msa}=0 \& \| \mathrm{l}=4.649487,-74.081154 \& \mathrm{spn}=0.121478,0$. $2635 \& \mathrm{t}=\mathrm{h} \& \mathrm{z}=13 \& \mathrm{msid}=112662661233841368429$. 0004705a6170a0b4a8f62

${ }^{26}$ El brasileño http://www.mapaocorrencias.site40.net/

27 http://www.lavoz.com.ar/monitor_ciudadano/

28 http://geo.defesasocial.mg.gov.br/ los interprete a su manera, lo que empeora las cosas, sobre todo cuando bajo una denominación genérica se agrupa un conjunto de contravenciones que guardan relación entre sí perdiéndose por el camino el matiz de grado, de gravedad o de intensidad.

En cuanto a los aspectos formales, es preciso reconocer que casi ninguna de las páginas utiliza una estética tremendista de iconos en la representación de los delitos, que contribuiría a configurar la estética del peligro de la que habla Wallace (2009).

\section{El clima político en que aparecen los mapas online del delito}

Como ya hemos dicho, la seguridad es una de las preocupaciones más importantes de los ciudadanos de los países iberoamericanos, habitualmente amplificada por la prensa ${ }^{29}$ que, además, al abordar las posibles soluciones, suele presentar esta cartografía como una herramienta que tiene que ayudar a reinstaurar la seguridad y el orden perdidos (Martini, 2007: 52). Todo ello concuerda en gran medida con dos de las premisas de la lógica actuarial, por un lado porque contribuye a la "transferencia del coste de los riesgos a la comunidad", cuando estos no se pueden evitar o controlar $y$, por otro, porque ayuda a la "acumulación de información sobre los riesgos" (Domínguez y Rodríguez, 2003: 333334), lo que propicia la expansión de estas web, que se presentan como un instrumento útil para que la ciudadanía asuma parte de la prevención del delito y, además, como hoja de ruta para los cuerpos policiales ${ }^{30}$. El clima

\footnotetext{
29 Encontramos un interesante análisis del tratamiento del delito por la prensa argentina en Martini, 2007. Para el caso chileno ver Dastres, Muzzopapa, Sáez y Spencer, 2005. Un repaso más somero del caso chileno en Jofré, 2006. Para algunos aspectos del caso ecuatoriano ver Cerbino, 2007.

${ }^{30}$ Como se desprende, por ejemplo, de la presentación de Delitos Ecuador: "Quiere ser un espacio para estar informados y para informar a las autoridades que son las que deben tomar las decisiones para brindarnos seguridad". Ver http://www.delitosecuador.com/page/index/1. Por su parte el jefe de la brigada de narcóticos de Mendoza admite al periódico Los Andes que utilizan la web el Mapa del Delito (http://www.elmapadeldelito.com.ar/), como orientación acerca de dónde se mueve la droga en el Gran Mendoza. Ver Barros, 2009.
} 
en el que surgen estos mapas es el de la confusión y la saturación informativa en torno al tema de la seguridad, y se han convertido en un elemento permanente de la agenda política y del debate ciudadano ${ }^{31}$, así como en un medio de propaganda electoral.

Veamos cuáles son los argumentos con los que se justifican algunos mapas online del delito puestos en marcha por particulares u ONG: "Hagamos pública la denuncia de hechos delictivos. Para que todos estemos informados. Para que todos estemos prevenidos. Para que no haya impunidad. Por un Bariloche mejor"32. "El momento en que una sociedad considera normal lo anormal hay un profundo peligro. La escalada delictiva en Ecuador, por momentos, Ilega a ser una anécdota más que contamos en las sobremesas, en el día a día. Se ha convertido en rutina. Nos toca directamente, a un familiar, al vecino, al amigo o al amigo del amigo. Es el momento que una sociedad unida pueda aportar para tratar de mejorar". Se trata, en su mayoría, de las divisas de la clase media, de aquella parte de la población que, según Heberecht, se encuentra amenazada con entrar a formar parte de la marginación y que se "siente abandonada por el Estado y, en concreto por la policía y la justicia, que ya no pueden garantizar su seguridad" (Heberecht, 2003: 360).

El segmento de población denominado competitivo, aunque también participa de este crime complex ${ }^{33}$ y hace suyo este dis-

\footnotetext{
31 Como se explica en el mexicano Mapa Delincuencial: "Somos ciudadanos indignados por la impunidad y preocupados por la delincuencia que creemos que una ciudadanía comprometida y participativa hará la diferencia. Sabemos que podemos formar parte de la solución y no solamente del problema". Ver el apartado de preguntas frecuentes de http:// www.mapadelincuencial.org.mx/index.php. Ver Corporación Latinobarómetro, 2010: 16-17.

32 Esto es lo que rezaba en la página de presentación de Delitos en Bariloche. Ver http://www.delitosenbariloche.com.ar/

33 El "crime complex" de la modernidad tardía es, según Garland, una construcción cultural caracterizada por un conjunto de actitudes, creencias y asunciones, como el hecho de encontrar como normal la existencia de tasas altas de delincuencia una intensa y generalizada inversión emocional en el problema del crimen; la politización y representación en términos emotivos de las cuestiones relacionadas con la delincuencia; el dominio de las políti-
}

curso, lo hace de otra manera, ya que puede permitirse adquirir seguridad en el mercado privado y tiene capacidad para emprender campañas masivas de concienciación pública, como el conocido caso Blumberg en Argentina, o las puestas en marcha en otros países, en las que se abogaba por la aplicación de las tácticas de tolerancia cero $(\mathrm{Mu}-$ rillo, 2008: 215-258) en la lucha contra el crimen, que hacen hincapié en la represión de las contravenciones más nimias. Además, como decíamos más arriba, en los últimos tiempos se ha consolidado aquella tendencia que responsabiliza a la ciudadanía de parte de su propia seguridad, esto se ha conseguido de diversas maneras, entre ellas mediante lo que se ha dado en llamar "asociación preventiva", expresión que define el pacto por el cual las agencias gubernamentales y no gubernamentales coordinan sus prácticas con el fin de incrementar la seguridad mediante la reducción de oportunidades y la concienciación sobre la problemática de la delincuencia (Garland, 2000: 349). Esto ha funcionado de manera más extensa en ámbitos diferentes del iberoamericano, donde aún es débil esta vinculación entre lo público y lo privado ${ }^{34}$, y ha dado lugar a estrategias comunitarias de prevención como las community watch. La debilidad de estas prácticas también contribuye a la expansión de las web del delito puestas en marcha por ciudadanos y ONG, que además se ayudan de las redes sociales para mantenerse informados. De hecho consideramos que se trata de la otra cara de la moneda del fenómeno de proliferación de barrios cercados y la utilización masiva de

cas públicas por una preocupación por la víctimas y la seguridad pública; una visón del estado de la justicia criminal como inadecuado o inefectivo; una generalización de las rutinas defensivas privadas y la existencia de un amplio mercado de seguridad privada; la institucionalización en los medios de comunicación de una concienciación sobre el delito. Ver Garland, 2000: 367-368. Ver también Garland, 2005: 211-216.

$34 \mathrm{Al}$ menos no funciona como en los Estados Unidos, por ejemplo. Hay, de todos modos, otros ámbitos de colaboración, como la permisividad para con la vigilancia privada en ciertos barrios de las ciudades y la edificación de comunidades cercadas. En todas ellas existe el problema de superposición de jurisdicciones y unos límites muy borrosos entre lo público y lo privado. 
seguridad privada por parte de los segmentos de población más acomodados.

Así, no extrañan afirmaciones como la que encontramos en la web venezolana Quiero $\mathrm{Paz}^{35}$ que persigue "generar información veraz y oportuna sobre los índices de criminalidad en el país que permitan fortalecer la democracia, garantizar los derechos humanos y el desarrollo integral de todos los ciudadanos". Tiene, por tanto, una doble finalidad: la prevención y la reposición de un estatus perdido. Igual que en la chilena ONG "Víctimas de la delincuencia"36, cuyo principal objetivo, aparte de "mejorar las condiciones de seguridad de la ciudadanía", es la reparación de las víctimas de la delincuencia ${ }^{37}$.

Tampoco debemos olvidar a la clase política que, sumándose a la moda del populismo punitivo ${ }^{38}$, encuentra en este instrumento un elemento valiosísimo en su carrera, colocando la seguridad en el centro del discurso electoral (Sozzo, 2009; Dammert y Salazar, 2009), prestando especial atención a aquellas contravenciones que ocurren en el espacio público y crean mayor alarma social, asociándolas a la pobreza e insistiendo en la incapacidad del sistema penal vigente ${ }^{39}$. Este discurso, al mismo tiempo, vuelve a poner sobre el tapete la perentoriedad de erradicar la delincuencia negando la evidencia que se ha constatado hace tiempo, a saber, la consustancialidad de esta al sistema económico y social en el que vivimos (Castells, 1995: 249322; Garland, 2005: 222; Maillard, 2002).

$35 \mathrm{http}: / / q u i e r o p a z . o r g / q u i e n e s s o m o s$

36 http://www.victimas.cl/content/view/208891/ ONG_V_ctimas_de_la_Delincuencia.html

37 Esto está muy relacionado con las nuevas estrategias en las que se pone el acento en la gestión de las consecuencias del delito más que en sus causas. Sobre la justicia restitutiva ver Garland, 2005: 206207.

${ }^{38}$ Según Anthony Bottoms (1995), que acuñó el término, la noción de populismo punitivo pretende mostrar a los políticos aprovechando y usando para los propios fines lo que ellos creen que es la postura punitiva pública.

39 Rangugni explica que esta construcción del problema de la seguridad no es fruto del azar sino que está relacionada con la emergencia del neoliberalismo como racionalidad política y de la estructuración de nuevas formas de actuar y de pensar que cristalizan en una mayor desigualdad y fragmentación social. Ver Rangugni, 2009: 23-24.
Así, se crea una "competencia electoral por el tema del delito" (Garland, 2005: 227), apelando al sentido común, a aquello que realmente le preocupa a la ciudadanía, desterrando cualquier opinión experta (Garland, 2005: 228). Al mismo tiempo, y como complemento de todo ello, en estos mapas se moviliza a los ciudadanos (Sozzo, 2009: 42) para que se conviertan en parte de la solución, denunciando los actos ilegales que hayan sufrido o presenciado, en una escenificación más que dudosa de un proceso de participación ciudadana ${ }^{40}$ sobre cuyos límites ya se ha hablado.

De nuevo es en Argentina donde este instrumento es más usado por la clase política, aunque también hemos hallado un buen ejemplo en Chile. Jorge Boasso, candidato a la intendencia de Rosario, explica en el mapa del delito de su página web que "este MAPA está hecho por y para la gente" 41 , frase en la que encontramos, además de una voluntad redentora en su conjunto, una cierta responsabilidad de la ciudadanía en el cometido de hacer su entorno más seguro. Igualmente, afirmaba en su campaña de 2011: "mi gobierno va a ser de todos y para todos". Pero no fue Boasso el primero en saltar a la arena pública con un mapa online de delitos, sino el diputado Francisco de Narváez, un exitoso empresario del sector de la comunicación que, consciente del poder de los medios, puso en marcha una campaña electoral en la cual la seguridad era uno de los pilares fundamentales. Lanzó el "Mapa de la Inseguridad"42, que tenía como escalas de búsqueda tanto la provincia como la ciudad de Buenos Aires, en el que se registraban los delitos ingresados por los usuarios junto con un comentario de los mismos. Al mismo tiempo organizó el grupo "Todos contra la

\footnotetext{
40 "Esto es un instrumento de participación y de información" declaraba sobre su Mapa del Delito de Rosario Jorge Boasso. Ver Boasso, 2009.

41 http://www.boasso24horas.com/web2/index.php?option $=$ com_content $\&$ view $=$ article $\&$ id $=475$ :rosario-segura\&catid=3: noticias-de-ultima-hora\&ltemid $=9$. Las mayúsculas del mapa tienen una connotación especial puesto que, dándose cuenta de lo expresiva que es la cartografía, Boasso incluye también en su página web un mapa de Baches de Rosario y un mapa de accidentes de tráfico.

42 http://www.mapadelainseguridad.com/
} 
inseguridad" en las redes sociales Facebook ${ }^{43}$ y Sonico ${ }^{44}$. Para rematar, el mapa tiene un blog ${ }^{45}$ en el que se explican y comentan los sucesos más luctuosos con titulares como: "Violencia exacerbada", "La inseguridad nos toca a todos" o "El Mapa de la Inseguridad lo advirtió", titular, este último, relacionado con los disparos a una chica embarazada por una banda de moto chorros en La Plata. A la vez, y en relación con todo esto, también lanzó un website denominado "La seguridad se hace" 46 , en el que daba su receta para una Argentina segura. Así, según de Narváez, la inseguridad se sustenta en el mal funcionamiento de la policía, las leyes, la justicia y las cárceles y propone, para hacer más eficientes los cuerpos policiales, la puesta en marcha de un Mapa Oficial del Delito en tiempo real. Como telón de fondo plantea un panorama apocalíptico en el que sube la tasa de delitos, sobre todo los graves, con una masa de jóvenes que no estudian ni trabajan, donde existen muchas probabilidades de exclusión y en el que crece la violencia familiar. En su plan, habría que "dotar a la policía de una nueva estrategia general orientada a la prosecución inteligente de la delincuencia" 47 y ello vendría de la mano de la tecnología y de ese mapa del delito, que la convertiría en un cuerpo que actuaría de manera proactiva en la represión del delito y que tendría como objetivo estratégico aumentar el riesgo de delinquir, proponiendo un modelo policial que ha de parecer omnipresente, ejerciendo así un poder disuasorio. Lógicamente, la ciudadanía, la comunidad, tiene que desempeñar un papel importante en todo este proceso, tomando el rol de vigilante (Garland, 2005: 209-211).

Menos trabajada es la propuesta del "Mapa del Delito de la Provincia de Santa $\mathrm{Fe}^{\prime \prime 48}$, publicado en 2009 como apoyo a la campaña política de Alberto Martínez, Secre-

\footnotetext{
43 http://www.facebook.com/group.php?gid=33019584537\#!/ group.php?gid $=33019584537 \& \mathrm{v}=$ wall

44 http://ar-es.sonico.com/g/968089980/todos-contrala-inseguridad

45 http://blog.mapadelainseguridad.com/

46 http://laseguridadsehace.com/

47 Ver el siguiente documento adjunto al mencionado website, página 11: http://laseguridadsehace.com/Archivo/Policia/Mapa_Delito/MapaOficialdelDelito.pdf

48 http://mapadeldelito.info/
}

tario General del sindicato policial APROPOL en esa provincia, como senador nacional. Los lemas de la campaña fueron "Un diputado por la seguridad" y "La inseguridad tiene solución si se respetan los derechos de los trabajadores policiales y penitenciarios". Este es un claro ejemplo de las políticas de línea dura, como se puede ver en su decálogo de medidas urgentes contra la criminalidad 49 . Conviene decir que este mapa, aunque aún se puede visitar online, solamente funcionó durante la campaña electoral mencionada y no ha habido entradas desde el año 2009 al no haber ganado el candidato el escaño de senador.

Algo parecido ocurrió con el "Mapa del Delito" $^{\prime 50}$ de Viña del Mar y Concón, poblaciones cercanas a Valparaíso, Chile, creado conjuntamente por el candidato a diputado Carlos Gómez y el concejal de la primera población Andrés Celis. Este duró poco y parece que funcionó mal, si tenemos en cuenta los comentarios de algunos usuarios en las noticias de los periódicos que anunciaban su puesta en marcha. De nuevo el lema del mapa (Información + participación = acción) tenía que ver con la participación ciudadana. Paralelamente se creó un blog y todo ello estaba conectado a las redes sociales

\footnotetext{
49 Se trata de las medidas siguientes: 1.- "Delincuentes presos, ciudadanos libres". 2.- Reconstrucción de la policía y el servicio penitenciario. (Amplio reconocimiento y reparación histórica). 3.- "Desatarle las manos a la policía". Apoyo al accionar policial con garantías amplias. "Dentro de la ley todo, fuera de la ley nada". 4.- Poner la justicia al servicio del bien común. 5.- Cumplimiento de la ley en forma estricta. Sin excarcelaciones en reincidencias. Sin conmutaciones. Delinque y va preso con juicio oral y público inmediato. 6.- Urgente avance en una política social integral a partir de una distribución de la riqueza nacional más equilibrada y con criterio de verdadera justicia social. 7.- Combate en el marco cultural a favor de la vida y la cultura del trabajo. 8.- Participación y control comunitario adecuado en las políticas de Estado garantizando una verdadera democracia al servicio del pueblo y con criterio de federalismo auténtico. 9.- Recuperación del espacio fuera del control del Estado. 10.- Desarticulación de las amplias redes del crimen organizado. Funcionarios que participen doble pena a cumplir sí o sí e inhabilitación perpetua y absoluta. Ver Sozzo, 2009: 42

50 http://www.mapadeldelito.cl
} 
Facebook $^{51}$ y Twitter $^{52}$. En él leemos la declaración de intenciones, donde instaba a la ciudadanía a participar y "ayudar a encontrar soluciones a este flagelo" 53 que es la delincuencia. En la información de Facebook se vuelve al lenguaje populista con afirmaciones del tipo: "para que la gente honesta esté libre y los delincuentes estén encerrados" 54 . Otra de las señas de identidad de esta web del delito fue su presentación en la manzana 666 de Viña del Mar, considerada la más peligrosa del municipio.

Para acabar, un pequeño comentario sobre un mapa del delito que nunca existió o que, al menos, nunca se hizo público. En la campaña de 2007 al gobierno de la provincia de Mendoza, el candidato Celso Jaque aseguraba que tenía el mapa del delito que les había costado dos años elaborar y con el cual preveían que, junto con otras medidas, reducirían en seis meses la tasa de delitos en un $30 \%$. Según uno de los organizadores de la campaña, esta propaganda fue clave para ganar las elecciones (Hirschbrand, 2007). El tema tiene importancia porque fue el detonante de esta oleada de webs en Argentina. El mapa, que no vio la luz, acabó volviéndose en su contra convirtiéndose en arma arrojadiza, en otras campañas, en manos de sus adversarios.

\section{Conclusiones}

Tal como hemos reiterado a lo largo de estas páginas, la investigación que enmarca el trabajo que aquí se presenta pretende ahondar en la relación existente entre la percepción de seguridad y ciertos factores territoriales, partiendo de la hipótesis de que hay un flujo en ambas direcciones. Desde esta perspectiva la cartografía online del de-

51 http://www.facebook.com/pages/MAPA-DEL-DELITO-CIUDADANOS-QUE-SE-INFORMAN-PARTICIPAN-Y-ACTUAN/

$52 \mathrm{http}: / /$ twitter.com/mapadeldelito

53 http://mapadeldelito.wordpress.com/2009/09/10/ definiciones-mapa-del-delito/

${ }^{54}$ Palabras que no sorprenden en un candidato que tenía como eslogan de campaña "mano firme, corazón grande", toda una lección de paternalismo que, por otra parte, parafrasea el lema de campaña de 2006 del que fuera presidente de Colombia, Álvaro Uribe. lito adquiere una relevancia social notable, al tratarse de una información territorial relacionada con los miedos y la sensación de seguridad. La convicción de que esta se está convirtiendo en un elemento muy importante en la conformación de nuestro entorno, y por tanto de la vida cotidiana, nos ha llevado a acometer un análisis riguroso de la misma desde un enfoque geográfico. En este artículo hemos desmenuzado las dieciocho páginas existentes en siete países de América Latina, atendiendo tanto a su contenido como a las circunstancias sociales, políticas y económicas que propiciaron su aparición y expansión, lo que consideramos un trabajo inexcusable para posteriormente avanzar en el estudio de sus efectos territoriales y sobre la percepción de seguridad, tarea que dejamos para otra publicación.

Estas páginas web aparecieron como consecuencia de la maduración de una serie de circunstancias como la consolidación de la participación en los procesos de planificación urbana, realizada con frecuencia de manera oportunista y poco rigurosa, la reflexión geográfica sobre las implicaciones territoriales de los delitos y los conflictos y la expansión de la denominada lógica actuarial.

Todo ello creó el caldo de cultivo para que la web 2.0 en expansión se convirtiese, entre otras cosas, en una plataforma para registrar este tipo de fenómenos sociales, crecimiento que, obviamente, no provenía de la preocupación por el delito o sus implicaciones territoriales sino que respondía a dinámicas de carácter general. Sus defensores, que la consideran imparable, argumentan básicamente en dos direcciones. Por un lado se refieren a las potencialidades económicas que encierra, ya que está sirviendo para activar una economía de colaboración, para lo que incluso se ha acuñado un término: wikinomics. Tendencia que está dando muestras de radicalización en lo que se ha dado en llamar crowdsourcing. La segunda línea argumental de sus apologistas tiene que ver con la aparición de una especie de inteligencia colectiva: los conocidos sistemas emergentes que ya hemos explicado.

Desde tal perspectiva las web del delito adquieren nuevas dimensiones, puesto que, del mismo modo que la colaboración genera 
valor y hace posible un funcionamiento eficiente que se ajusta de manera automática y dinámica, la denuncia colectiva de ciertos hechos se presenta como creadora de seguridad o, al menos, propiciadora de una mayor sensación de ella.

En este marco hemos estudiado el caso de los países de América Latina que disponían de estas páginas a finales de 2010, donde se muestran algunas tendencias con cierta claridad, lo que es especialmente relevante, por un lado, porque la seguridad ocupa un lugar destacado entre las preocupaciones de sus habitantes $y$, por otro, porque el crecimiento de los usuarios de internet ha sido muy notable en los últimos años: un 23\% entre 2009 y 2010 en el entorno iberoamericano. Como era de esperar la disponibilidad de las TIC es diferente de unos países a otros y el desarrollo de esta cartografía corre paralelo a su implantación y expansión.

Para entender la situación hemos de tener en cuenta que el acceso a internet es un fenómeno fundamentalmente urbano y relativamente débil en el ámbito doméstico en las zonas rurales, lo que nos hace pensar que las instalaciones públicas están desempeñando un papel importante, lo cual ha dado lugar al panorama que hemos descrito: Argentina (9 páginas del delito), Brasil (3), Chile (2), Colombia, Ecuador, México y Venezuela (con una página cada uno), un total, por tanto, de 18.

Es fácil observar, a partir de los datos que hemos aportado, que no hay una correlación exacta entre el despliegue y acceso a internet (mayor en Chile que en Argentina por ejemplo) y el número de sitios de este tipo existentes, lo cual quiere decir que hay también otros factores sociales, económicos o culturales que contribuyen a su aparición.

En estas condiciones cabría proponer la siguiente explicación: hay diferentes escalones en la implantación de las TIC y en cada uno de ellos cambia el peso relativo de los distintos elementos que intervienen en la gestación de las web del delito. En el nivel 1 estarían los países (Argentina, Chile y Brasil) que han traspasado el umbral de las limitaciones tecnológicas $y$, por tanto, estas dejan de ser determinantes, por lo que entran en juego otros elementos que, en tales circunstancias, son los relevantes, como la formación, la extensión de las clases medias, las tasas de insatisfacción institucional y el grado de generalización de la sensación de inseguridad, tal como hemos explicado. A todo ello habría que añadirle elementos de carácter político, en sociedades en las que puede prosperar con mayor facilidad lo que se conoce como populismo punitivo. Este conjunto de factores ayuda a explicar la preeminencia de Argentina sobre Chile y Brasil. En el nivel 2 encontramos los países (Colombia, Ecuador, México y Venezuela) que están en ese umbral en el que el acceso a las TIC no ha alcanzado masa crítica y limita la expansión de esta web, lo cual relativiza, o disminuye la relevancia de otros factores de orden social o económico como los que hemos enumerado con anterioridad. De todos modos, la oportunidad política de este tipo de páginas y la utilización de la sensación de inseguridad siguen siendo importantes. Finalmente, en el nivel 3, estarían el resto de países iberoamericanos que todavía no han Ilegado al grado de implantación y uso de internet como para que prosperen estas páginas o se contemplen como una herramienta accesible y útil para el control de la delincuencia, que es como se suelen presentar en aquellos lugares donde han comenzado a proliferar.

Es importante también reflexionar sobre su titularidad, pues están vinculadas a particulares u ONG (el 50\%), a políticos electos o en campaña $\left(22^{\prime} 2 \%\right)$, a organismos gubernamentales $\left(16^{\prime} 6 \%\right)$, a periódicos $\left(5^{\prime} 5 \%\right.$ ) y a organizaciones empresariales (5'5\%) lo cual dibuja un panorama muy diferente del que habíamos visto en el análisis global y, especialmente, en el entorno anglosajón. Conviene además señalar que los datos cartografiados son introducidos por los propios usuarios en el $61 \%$ de los casos, sin que apenas exista ningún sistema para contrastar la veracidad de dicha información, lo que arroja bastantes dudas sobre la fiabilidad de los mapas resultantes. Por otro lado no se definen con precisión ni se tipifican las categorías delictivas, lo que tiende a aumentar la confusión.

Finalmente, hemos constatado que, por lo general, se suelen representar aquellas contravenciones que crean una mayor alarma social, como pueden ser los robos, el tráfico 
de drogas o los secuestros, por poner algunos ejemplos, hechos que suelen ocurrir en el espacio público. Los iconos utilizados suelen ser bastante neutros, aproximándose a un "mapa de chinchetas".

A la vista de este panorama convendría hacer un sucinto repaso de los problemas que acompañan a esta cartografía en la red para, posteriormente, poder señalar algunos factores que tiendan a paliarlos. Podríamos agrupar los inconvenientes en dos categorías, por un lado los de carácter general y, por otro, aquellos que provienen de las condiciones particulares del entorno territorial estudiado.

Entre los primeros estarían los derivados de la propia idiosincrasia de la web del delito, muy acorde con el discurso de la lógica actuarial, que restringe la intervención a una mera gestión de los riesgos, para situarlos en cotas aceptables socialmente, soslayando la actuación sobre las causas. Igualmente, la web 2.0, aunque parece imparable por su potencialidad, en diferentes ámbitos y especialmente en el económico, también presenta problemas de importancia, ya que, en la medida en que absorbe toda la información que le llega, está propiciando el auge de las opiniones mayoritarias que, en último término, pueden aparecer como la única verdad, de manera que se silencian las minorías o las voces disidentes y desaparece, haciéndose invisible, el discurso de quienes no tienen acceso a los instrumentos necesarios. Los sistemas emergentes, saludados encomiásticamente por muchos, también han sido duramente criticados por la entronización del aficionado a la hora de afrontar determinados problemas. Las consecuencias que ello tiene en asuntos de relevancia social, como la sensación de seguridad de la población, deberán estudiarse con detenimiento, pero es previsible que podrían ser dignas de consideración.

En la segunda categoría hay que señalar los inconvenientes propios de la situación concreta que hemos analizado y que, básicamente, son de dos tipos. Como hemos visto, estas páginas, a menudo, están siendo utilizadas políticamente con intereses partidistas, lo que introduce un elemento más de incertidumbre y subjetividad, con las consecuencias negativas que ello puede tener para reforzar la cohesión y para abordar desde una pers- pectiva diferente la cuestión de la sensación de seguridad.

Por otro lado, pueden contribuir a profundizar las brechas que separan a diferentes sectores sociales, porque frente a los temores las clases altas tienen el recurso de la seguridad privada, cercando y protegiendo sus lugares, las clases medias utilizan, en la medida de sus posibilidades, instrumentos parecidos $y$, además, tienen herramientas como las que la red les ofrece, a pesar de su dudosa fiabilidad en ocasiones. Pero los excluidos del acceso a las TIC, que suelen ser los sectores más desfavorecidos, ni siquiera disponen de esas posibilidades, con lo que la distancia respecto a los otros se acrecienta, al tiempo que, además, suelen desempeñar el papel del principal sospechoso.

Nos encontramos, por tanto, frente a un dilema, o una aparente contradicción, que tiene consecuencias sociales y territoriales de importancia. La web del delito, en general, pero especialmente en Iberoamérica, presenta serios problemas de credibilidad, suele ser instrumentalizada políticamente con frecuencia, no contribuye a actuar sobre las causas de los problemas ni a favorecer la cohesión social. Propicia la confusión entre la realidad, que es inaprensible, y un dibujo muy subjetivo y a menudo interesado, como es el mapa que se encuentra en internet.

Pero, a la par, es percibida, y presentada tendenciosamente, como un instrumento eficaz en la lucha contra la delincuencia y, por tanto, útil para reforzar la sensación de seguridad. Además, la web 2.0 parece imparable por su implantación en ámbitos muy diversos, por las externalidades que genera y por su potencialidad económica, todo ello a pesar de los problemas que plantea.

Este escenario está, sin duda, Ileno de contradicciones, lo que nos obliga a esbozar algunas medidas que podrían paliar los inconvenientes más notorios de este instrumento, en la medida en que, dado el contexto general, su expansión parece muy probable, a lo que contribuirá, al menos a medio plazo, el ambiente político. Por todo ello, partiendo de la idea de que las web del delito continuarán prosperando en los próximos años, parece necesario reflexionar sobre la manera 
de limitar los perjuicios que se pueden seguir de su uso actual.

Fundamentalmente habría que actuar en dos direcciones. Es inexcusable insistir en la idea de que la delincuencia, y su localización, son problemas complejos que tienen que ver con dinámicas globales de carácter social y económico, por lo que es imprescindible intervenir en tal sentido si se pretende avanzar hacia una sociedad más justa y más segura, lo contrario lleva necesariamente a la instrumentalización interesada de los temores. Este mensaje ha de ir permanentemente unido a la cartografía que hallamos en la red $y$, en consecuencia, es responsabilidad de sus titulares insistir sobre ello.

Por otro lado, en la medida en que existan y sean públicas, es necesario que cumplan con unos requisitos estrictos de veracidad de la información introducida, aunque se debería recordar que la incorporación de datos, aunque sean ciertos, ya genera un resultado sesgado, puesto que no toda la población está en las mismas condiciones de acceso a la red $y$, aunque lo estuviese, existe una brecha notable entre lo conocido y la propia realidad ${ }^{55}$. Se trataría, en definitiva, de controlar la fiabilidad de lo cartografiado, a pesar de que ello no garantiza en absoluto la certidumbre del panorama general que arroja el mapa.

Es preciso seguir con gran atención, en los próximos años, la evolución de esta cartografía, en diferentes ámbitos, dadas sus enormes repercusiones sociales y territoriales.

\section{Referencias bibliográficas}

BARROS, C. El consumo de cocaína aumentó $30 \%$ en el último año en Mendoza. Los Andes, 2009, 14 de enero. Disponible en internet:

http://www.losandes.com.ar/notas/2009/1/14/sociedad-403111.asp

BECK, U. La sociedad del riesgo global. Madrid: Siglo XXI, 2002.

\footnotetext{
55 En este artículo hemos soslayado el tema de la construcción social de la delincuencia, asunto del que nos hemos ocupado en otras ocasiones
}

BOTTOMS, A. The philosophy and politics of punishment and sentencing. In: CLARKSON, C. \& MORGAN, R. The politics of sentencing reform. Oxford: Clarendon Press, 1995, p. 17-50.

BOUZA, F. Tendencias a la desigualdad en Internet: la brecha digital (digital divide) en España. En: TEZANOS, J.F.; TORTOSA, J.M. y ALAMINOS, A.F. Tendencias en desvertebración social y en políticas de solidaridad. Madrid: Editorial Sistema, 2003, p. 93-121.

CAMPOS VENUTI, G. La terza generazione dell'urbanistica. Milan: Franco Angeli, 1990.

CAPEL, H. La enseñanza digital, los campus virtuales y la geografía. Ar@cne: Revista Eléctronica de Recursos en Internet sobre Geografía y Ciencias Sociales, 2009, № 125. Disponible en internet: http://www.ub.es/ geocrit/aracne/aracne-125.htm

CASTELLS, M. La ciudad informacional. Madrid: Alianza, 1995.

CERBINO, M. EI (en)cubrimiento de la inseguridad o el "estado de hecho" mediático. Nueva Sociedad, 2007, No 208, p. 86-102.

CIMOLI, M. (coordinador). Las TIC para el crecimiento y la igualdad: renovando estrategias de la sociedad de la información. Santiago de Chile: CEPAL / Naciones Unidas, 2010.

COMSCORE. Situación de Internet en Latinoamérica. Santiago de Chile: ComSCORE, 2010.

CORPORACIÓN LATINOBARÓMETRO. Informe 2010. Santiago de Chile: Corporación Latinobarómetro, 2010.

CRESPI, A. Sociedad de la información: Análisis de modelos y tendencias. BarceIona: Tesis de Maestría de la UPC, 2010. Disponible en internet: http://hdl.handle. net/2099.1/9588.

DAMMERT, L. Violencia criminal y seguridad ciudadana en Chile. Santiago de Chile: CEPAL, 2005.

DAMMERT, L. y MALONE, M.F.T. Inseguridad y temor en la Argentina: el impacto 
de la confianza en la policía y la corrupción sobre la percepción ciudadana del crimen. Desarrollo Económico, 2002, Vol. 42, № 166, p. 285-301.

DAMMERT, L. y SALAZAR, F. ¿Duros con el delito? Populismo e inseguridad en América Latina. Santiago de Chile: FLACSO-CHILE, 2009.

DASTRES, C.; SPENCER, C.; MUZZOPAPPA, E. y SÁEZ, C. La construcción de noticias sobre Seguridad Ciudadana en prensa escrita y televisión. ¿Posicionamiento, distorsión o comprensión? Santiago de Chile: CESC, 2005.

DE CASTRO, C. La geografía de la vida cotidiana: de los mapas cognitivos al prejuicio regional. Barcelona: Ediciones del Serbal, 1997.

DE CASTRO, C. Mapas mentales. Pamplona: Universidad Pública de Navarra, 2004.

DOMÍNGUEZ, J.L. y RODRÍGUEZ, A. Lógica actuarial, seguridad y sistema de justicia. En: DA AGRA, C. La seguridad en la sociedad del riesgo. Barcelona: Atelier, 2003, p. 329351.

FRACASSO, L. Planificación comunitaria y participación en los procesos de decisión: categorías de análisis y argumentos. Biblio3W: Revista Bibliográfica de Geografía y Ciencias Sociales, 2000, Vol. 5, № 216. Disponible en internet: www.ub.edu/geocrit/b3w-216.htm

FRAILE, P. y BONASTRA, Q. Espacio, delincuencia y seguridad: hacia el diseño de un modelo de análisis territorial. Boletín de la Asociación de Geógrafos Españoles, 2011, № 57, p. 123-146.

FRAILE, P. y BONASTRA, Q. Seguridad y mapas online del delito: la otra cara de la participación ciudadana. Scripta Nova: Revista Electrónica de Geografía y Ciencias Sociales, 2010, Vol. 14, № 331-12. Disponible en internet: http://www.ub.es/geocrit/sn/sn-331/ sn-331-12.htm

FRAILE, P.; BONASTRA, Q.; RODRÍGUEZ, G. y ARELLA, C. Paisaje ciudadano, delito y percepción de la inseguridad: investigación interdisciplinar del medio urbano. Madrid: Dykinson, 2006.

FRAILE, P.; BONASTRA, Q.; RODRÍGUEZ, G. y ARELLA, C. Seguridad, temores y paisaje urbano. Barcelona: Ediciones del Serbal, 2010.

GARLAND, D. La cultura del control. Crimen y orden social en la sociedad contemporánea. Barcelona: Gedisa, 2005.

GARLAND, D. The Culture of High Crime Societies. Some Preconditions in 'Law an Order' Policies. British Journal of Criminology, 2000, No 40, p. 347-375.

HEALEY, P. Collaborative Planning. Shaping Places in Fragmented Societies. Hounmills: MacMillan, 1997.

HEBBERECHT, P. Sociedad de riesgos y política de seguridad. En: DA AGRA, C. La seguridad en la sociedad del riesgo. Barcelona: Atelier, 2003, p. 353-365.

HIRSCHBRAND, J. El "mapa del delito": la realidad superó la propaganda". Mdzonline, 2007, 5 de noviembre. Disponible en internet: http://www.mdzol.com/mdz/ nota/15163\%5EEl-mapa-del-delito-de-Jaquees-el-muestreo-de-denuncias-judicales.

IGLESIAS, M. Indicador de la Sociedad de la Información (ISI). Situación de las Tecnologías de la Información en Argentina, Brasil, Chile, Colombia, México y Perú. Madrid: Everis, CELA-IESE Bussines School, 2010.

JOFRÉ, R. Seguridad ciudadana y estrategias de comunicación en Chile. En: GERVER, E. Políticas de seguridad ciudadana y comunicación. La agenda ausente en el Cono Sur. Santiago de Chile: Centro de Competencia en Comunicación para América Latina, 2006, p. 79-90.

JOHNSON, S. Sistemas emergentes. O qué tienen en común hormigas, neuronas, ciudades y software. Madrid: Turner-F.C.E., 2003.

LA CAPITAL. Boasso pone en marcha su mapa del delito en la ciudad. La Capital, 2009, 4 de marzo. Disponible en inter- 
net: http://www.lacapital.com.ar/contenidos/2009/03/04/noticia_0028.html

LA NACIÓN. El delito creció 15,5\% en Buenos Aires. La Nación, 2009, 27 de marzo. Disponible en internet: http://www.lanacion. com.ar/nota.asp?nota_id=1112618

LINDÓN, A. La construcción social de los paisajes del miedo. En: NOGUÉ, J. (editor). La construcción social del paisaje. Madrid: Biblioteca Nueva, 2007

LINDÓN, A.; AGUILAR, M.Á. y HIERNAUX, D. Lugares e imaginarios en la metrópolis. Rubí: Antrophos, 2006.

MANIEWICZ, M. Perfiles estadísticos de la sociedad de la información 2009. Región de América. Ginebra: Unión Internacional de Telecomunicaciones, 2009.

MARTINI, S. Argentina. Prensa gráfica, delito y seguridad. En: REY, G. Los relatos periodísticos del crimen. Cómo se cuenta el delito en la prensa escrita latinoamericana. Bogotá: Centro de Competencia en Comunicación para América Latina, 2007, p. 21-54.

MURILLO, S. Colonizar el dolor. La interpelación ideológica del Banco Mundial en América Latina. El caso argentino desde Blumberg a Cromañón. Buenos Aires: CLACSO, 2008.

PIN, J.R. Situación de la tecnologías de la información en Latinoamerica, la Unión Europea y EE.UU. Especial referencia a los casos de Argentina, Brasil, Chile, Colombia, México y Perú. Madrid: Everis, CELA-IESE Business School, 2011.
PISANI, F. y PIOTET, D. La alquimia de las multitudes. Cómo la web está cambiando el mundo. Barcelona: Paidós, 2009.

RANGUGNI, V. Emergencia, modos de problematización y gobierno de la in/seguridad en la Argentina neoliberal. Delito y Sociedad, 2009, № 27, p. 23-43.

ROSE, N. Powers of freedom: reframing political thought. Cambridge: Cambidge University Press, 1999.

SOZZO, M. Populismo punitivo, proyecto normalizador y "prisión depósito" en Argentina. Sistema Penal \& Violencia, 2009, Vol. 1, $N^{\circ} 1$, p. 33-65.

TAPSCOTT, D. \& WILLIAMS, A. Wikinomics. How Mass Collaboration Changes Everything. New York: Portfolio, 2006.

TUPIZA, A. La cartografía delictual y la seguridad ciudadana. Ciudad Segura, 2007, $\mathrm{N}^{\circ} 17$, p. 4-9.

UNITED NATIONS DEVELOPMENT PROGRAM. Human Development Report 2010. New York: UNDP/Palmagrave Macmillan, 2010.

VMASV. Crean "Mapa del Delito" en Viña del Mar. Vmasv, 2009, 23 de septiembre. Disponible en internet: http://www.vmasv.cl/ historico/regionales/vina-del-mar/9046-creanqmapa-del-delitoq-en-vina-del-mar.html

WALLACE, A. Mapping City Crime and the New Aesthetic of Danger. Journal of Visual Culture, 2009, Vol. 8, No 1, p. 5-24. 
